\section{Status of bipolar disorder research}

\author{
Bibliometric study
}

SARAH CLEMENT, SWARAN P. SINGH and TOM BURNS
Is bipolar disorder schizophrenia's neglected little sister in relation to research? Goodwin asserted that there is a significant dearth of research on bipolar disorder based on his observation that there were six times more EMBASE publications on schizophrenia than on bipolar disorder (Goodwin, 2000). However, the author used a basic textword search (bipolar or mania $v$. schizophrenia) that would have missed papers on manic-depressive psychosis, for example. To obtain a fair assessment of whether bipolar disorder is underresearched relative to schizophrenia, sophisticated searches across a number of research-related databases are needed. This methodology can be used to examine not only literature size, but also indicators of research activity such as the number of ongoing projects, research funding awards and specialist journals. Furthermore, it can be used to illustrate how research activity changes over time and across different scientific fields.

\section{AIMS}

The main aim of this study is to compare levels of research activity in bipolar disorder and schizophrenia. The study's subsidiary aims are: to examine whether the relative size of the medical literature on bipolar disorder and schizophrenia varies over time; and to examine whether the relative size of the medical literature on bipolar disorder and schizophrenia varies across different scientific fields.

\section{METHOD}

\section{Indicators of research activity}

Nine computerised databases that provide indicators of research activity were identified and interrogated. The databases and the types of research activity that they indicate are described in Table 1.
Searching took place in March 2002. For the literature-searching databases, the period searched began at the databases' earliest year and ended at the year 2000, the most recent year for which complete data were available. For the other databases, the complete data-set was searched. The search strategies used were chosen on the advice of an information specialist. Searching under medical subject heading was conducted in four of the databases (Medline, EMBASE, PsycINFO and CINAHL). This type of searching draws together under one heading publications that may have used many different terms for a subject. It was not used in the Cochrane searches because, at the time of searching, the database had a backlog in attaching these headings, and pre-testing showed that searching under medical subject heading would have missed systematic reviews on bipolar disorder. Similarly, medical subject headings were not used for the National Research Register search because it has the same search system as the Cochrane Library. None of the other databases had the facility for searching under medical subject heading, therefore textword searching was used. The 'focus' option was used for all databases that had it, to restrict the searches to publications that focused on the illnesses in question. No restriction was placed on the type of publication in the literature-searching databases. When it was available, the 'explode' function was used, to ensure that relevant sub-categories of disease were included. The search strategies used are shown in Table 1.

In addition, one database, Medline, was used to examine changes over time and differences across scientific fields within bipolar disorder and schizophrenia research. Using the Medline search strategy shown in Table 1, comparisons were made between the number of bipolar and schizophrenia publications over 5 -year periods between 1966 and 2000. To investigate differences across scientific fields, the $\mathbf{1 2}$ Medline subheadings with the highest numbers of publications within them for bipolar disorder and schizophrenia were examined.

\section{Analysis}

The extent of any disparity between levels of research activity for bipolar disorder and schizophrenia was demonstrated by presenting the numbers of publications/ 
Table I Databases and search strategies

\begin{tabular}{|c|c|c|c|}
\hline Database & $\begin{array}{l}\text { Research activity } \\
\text { indicated }\end{array}$ & $\begin{array}{l}\text { Period/edition } \\
\text { searched }\end{array}$ & Search strategy' \\
\hline $\begin{array}{l}\text { EMBASE (Institute for Scientific } \\
\text { Information) }\end{array}$ & Published medical research & $1980-2000$ & $\begin{array}{l}\text { MANIC DEPRESSIVE PSYCHOSIS or MANIA } v \text {. } \\
\text { SCHIZOPHRENIA }\end{array}$ \\
\hline $\begin{array}{l}\text { PsyclNFO (American } \\
\text { Psychological Association) }\end{array}$ & $\begin{array}{l}\text { Published psychological } \\
\text { research }\end{array}$ & $1887-2000$ & BIPOLAR DISORDER or MANIA v. SCHIZOPHRENIA \\
\hline $\begin{array}{l}\text { CINAHL (Cumulative Index to } \\
\text { Nursing and Allied Health } \\
\text { Literature) }\end{array}$ & $\begin{array}{l}\text { Published nursing and allied } \\
\text { health research }\end{array}$ & $1982-2000$ & BIPOLAR DISORDER v. SCHIZOPHRENIA \\
\hline $\begin{array}{l}\text { Cochrane Controlled Trials } \\
\text { Register } \\
\text { (http://www.update-software.com/ } \\
\text { Cochrane/default.HTM) }\end{array}$ & $\begin{array}{l}\text { Current and completed } \\
\text { controlled trials }\end{array}$ & $\begin{array}{l}\text { Cochrane Library, } \\
2002 \text {, issue I }\end{array}$ & $\begin{array}{l}\text { (((bipolar or bi-polar) next (disorder* or affective)) or } \\
\quad(\text { manic or mania })) \text { v. schizophreni* [title search] }\end{array}$ \\
\hline $\begin{array}{l}\text { Cochrane Database of } \\
\text { Systematic Reviews } \\
\text { (http://www.update-software.com/ } \\
\text { Cochrane/default.HTM) }\end{array}$ & $\begin{array}{l}\text { Cochrane systematic reviews } \\
\text { completed and in progress }\end{array}$ & $\begin{array}{l}\text { Cochrane Library, } \\
2002 \text {, issue I }\end{array}$ & $\begin{array}{l}\text { (((bipolar or bi-polar) next (disorder* or affective)) or } \\
(\text { manic or mania) }) \text { v. schizophreni* [title search on } \\
\text { reviews and protocols] }\end{array}$ \\
\hline $\begin{array}{l}\text { National Research Register } \\
\text { (Department of Health, } \\
\text { http://www.update-software.com/ } \\
\text { national) }\end{array}$ & $\begin{array}{l}\text { Ongoing NHS-related UK } \\
\text { research projects }\end{array}$ & 2002 , issue I & $\begin{array}{l}\text { (((bipolar or bi-polar) next (disorder* or affective)) or } \\
\text { (manic or mania)) v. schizophreni* [ongoing projects } \\
\text { only, title search] }\end{array}$ \\
\hline $\begin{array}{l}\text { Journal Citation Reports (ISI } \\
\text { Web of Science) }\end{array}$ & $\begin{array}{l}\text { Specialist journals devoted to } \\
\text { the two conditions }\end{array}$ & 2000 edition & $\begin{array}{l}\text { bipolar or bi-polar or manic or mania or schizophrenia or } \\
\text { schizophrenic [search on words in journal name] }\end{array}$ \\
\hline $\begin{array}{l}\text { R\&D Information (Department } \\
\text { of Health, http://www.rdinfo.org.uk) }\end{array}$ & $\begin{array}{l}\text { Research funding awards } \\
\text { making specific mention } \\
\text { of bipolar disorder or } \\
\text { schizophrenia }\end{array}$ & Accessed I3/3/02 & $\begin{array}{l}\text { bipolar or bi-polar or manic or mania or schizophrenia or } \\
\text { schizophrenic [freetext search of text describing awards] }\end{array}$ \\
\hline
\end{tabular}

I. Search terms under medical subject heading appear in upper case and those for textword searching appear in lower case. The asterisks denote wildcards, e.g.' 'disorder*' will search for 'disorder', 'disordered', 'disorders', etc.

projects/journals/funding awards for the two conditions in ratio format (bipolar disorder:schizophrenia, factored down).

In the analysis of Medline data on changes over time and across scientific fields, $\chi^{2}$ tests were undertaken. To examine where any differences lay, Pearson residuals were produced (Hosmer \& Lemeshow, 2000) and those exceeding \pm 1.96 (the critical $Z$-value for the $5 \%$ significance level) were considered significant.

\section{RESULTS}

The range of ratios (bipolar disorder:schizophrenia) across the nine research activity indicators was from 1:1.3 for research funding awards to 1:7.6 for clinical trials. This means that there was a relative excess of research activity on
Table 2 Levels and ratios of research activity on bipolar disorder and schizophrenia

\begin{tabular}{|c|c|c|c|}
\hline Indicator of research activity & Bipolar disorder (BD) & Schizophrenia (SZ) & Ratio (BD:SZ) \\
\hline Medline publications 1966-2000 & 9612 & 31550 & $\mathrm{I}: 3.3$ \\
\hline EMBASE publications $1980-2000$ & 7709 & 24989 & $\mathrm{I}: 3.2$ \\
\hline PsycINFO publications I887-2000 & 6832 & 31398 & $\mathrm{I}: 4.6$ \\
\hline $\begin{array}{l}\text { CINAHL (nursing/allied health) } \\
\text { publications 1982-2000 }\end{array}$ & 279 & 1277 & $\mathrm{I}: 4.6$ \\
\hline $\begin{array}{l}\text { Clinical trials in Cochrane } \\
\text { Controlled Trials Register } 2002\end{array}$ & 473 & 3580 & $\mathrm{I}: 7.6$ \\
\hline $\begin{array}{l}\text { Cochrane systematic reviews (in } \\
\text { progress and completed) } 2002\end{array}$ & 9 & 48 & $\mathrm{I}: 5.3$ \\
\hline $\begin{array}{l}\text { Current projects on National } \\
\text { Research Register } 2002\end{array}$ & 31 & 106 & $\mathrm{I}: 3.4$ \\
\hline $\begin{array}{l}\text { Specialist journals listed in Journal } \\
\text { Citation Reports } 2000\end{array}$ & 0 & 2 & $\begin{array}{l}\text { Cannot be } \\
\text { calculated }\end{array}$ \\
\hline $\begin{array}{l}\text { Research funding awards listed in } \\
\text { R\&D Information } 2002\end{array}$ & 10 & 13 & $\mathrm{I}: \mathrm{I} .3$ \\
\hline
\end{tabular}


Table 3 Number and ratio of Medline publications on bipolar disorder and schizophrenia across 5-year periods between 1966 and 2000

\begin{tabular}{lcccc}
\hline Time period & $\begin{array}{c}\text { Number of bipolar disorder } \\
\text { publications (Pearson } \\
\text { residual) }\end{array}$ & $\begin{array}{c}\text { Number of schizophrenia } \\
\text { publications (Pearson } \\
\text { residual) }\end{array}$ & $\begin{array}{c}\text { Ratio of bipolar disorder to } \\
\text { schizophrenia publications }\end{array}$ & $\begin{array}{c}\text { Absolute difference in number } \\
\text { of bipolar disorder and } \\
\text { schizophrenia publications }\end{array}$ \\
\hline $1966-1970$ & $631(-8.3)$ & $3136(4.6)$ & $1: 5.0$ & 2505 \\
$1971-1975$ & $802(-3.4)$ & $3079(1.9)$ & $1: 3.8$ & 2277 \\
$1976-1980$ & $1034(-0.3)$ & $3442(0.2)$ & $1: 3.3$ & 2408 \\
$1981-1985$ & $1380(6.5)$ & $3589(-3.6)$ & $1: 2.6$ & 2209 \\
$1986-1990$ & $1704(6.9)$ & $4474(-3.8)$ & $1: 2.6$ & 2770 \\
$1991-1995$ & $1712(-3.1)$ & $6202 \quad(1.7)$ & $1: 3.6$ & 4490 \\
$1996-2000$ & $2349(-0.2)$ & $7685(-0.1)$ & $1: 3.3$ & 5336 \\
Total & 9612 & 31607 & $1: 3.3$ & 21995 \\
\hline
\end{tabular}

Table 4 Number and ratio of Medline publications on bipolar disorder and schizophrenia across scientific fields

\begin{tabular}{|c|c|c|c|}
\hline $\begin{array}{l}\text { Scientific field } \\
\text { (Medline subheading) }\end{array}$ & $\begin{array}{c}\text { Number of bipolar disorder } \\
\text { publications (Pearson residual) }\end{array}$ & $\begin{array}{l}\text { Number of schizophrenia publications } \\
\text { (Pearson residual) }\end{array}$ & $\begin{array}{l}\text { Ratio of bipolar disorder to } \\
\text { schizophrenia publications }\end{array}$ \\
\hline Genetics & $990 \quad(12.5)$ & $2615(-6.0)$ & $\mathrm{I}: 2.6$ \\
\hline Diagnosis & $1238 \quad(0.5)$ & $5353(-0.2)$ & $\mathrm{I}: 4.3$ \\
\hline Metabolism & $240 \quad(0.1)$ & $1051 \quad(0.0)$ & $\mathrm{I}: 4.4$ \\
\hline Pathology & $64(-6.1)$ & $661 \quad(2.9)$ & $\mathrm{I}: 10.3$ \\
\hline Physiopathology & $414(-5.8)$ & 2560 & $\mathrm{I}: 6.2$ \\
\hline Blood & $411 \quad(10.2)$ & $942(-4.8)$ & $\mathrm{I}: 2.3$ \\
\hline Drug therapy & $2806 \quad(24.1)$ & $6845(-11.5)$ & $\mathrm{I}: 2.4$ \\
\hline Complications & $312 \quad(0.4)$ & $1336(-0.2)$ & $\mathrm{I}: 4.3$ \\
\hline Therapy & $451(-4.2)$ & $2519 \quad(2.0)$ & $\mathrm{I}: 5.6$ \\
\hline Psychology & $886(-23.8)$ & $9551 \quad$ (II.3) & $\mathrm{I}: 10.8$ \\
\hline Total & 8471 & 36133 & $\mathrm{I}: 4.4$ \\
\hline
\end{tabular}

I. The scientific fields studied were the 12 Medline subheadings that had the largest number of bipolar disorder and schizophrenia publications.

schizophrenia for all of the indicators examined but that the magnitude of the excess varied widely, depending on the particular indicator examined (see Table 2).

The investigation into the number of publications on bipolar disorder and schizophrenia during 5-year periods between 1966 and 2000 showed that the bipolar:schizophrenia ratio of publications varied from 1:2.6 in the 1980s to 1:5.0 in the late 1960s (see Table 3). There was a significant relationship between the type of disorder the publication was about and the time period $\left(\chi^{2}=236.82, P<0.0001\right)$. Examination of the Pearson residuals suggests a U-shaped pattern, with bipolar disorder publications being most underrepresented between 1966 and 1975, and again between 1991 and 1995, and least underrepresented between 1981 and 1990 . The absolute difference in the number of bipolar disorder and schizophrenia publications in the most recent time period examined (1996-2000) was over twice that in the earliest time period (1966-1970).

Investigation of the number of bipolar disorder and schizophrenia publications under the 12 main Medline subheadings indicated that the disparity was much greater in some scientific fields than in others $\left(\chi^{2}=2087.07, P<0.0001\right)$ (see Table 4). Examination of the Pearson residuals revealed that disparities were significant for 9 of the 12 scientific fields. The areas where the residuals indicated that bipolar disorder was most underrepresented were rehabilitation (with a 27-fold relative excess of schizophrenia publications), psychology (with a 11-fold relative excess) and pathology (with a 10 -fold relative excess).

\section{DISCUSSION}

Using a standardised methodology and sophisticated search techniques across a comprehensive range of research-related databases, we have demonstrated that, on all the indicators of research activity examined, bipolar disorder is underrepresented relative to schizophrenia. We found no evidence that the disparity is declining over time; indeed, in absolute terms, the disparity is increasing. 
It is important to consider the following limitations of this study. Textword searching was the only form of searching possible on some of the databases. This may have resulted in relevant items being missed or irrelevant ones being included. Where searching under medical subject heading was used, indexing errors may have distorted the findings. In EMBASE, the lack of a bipolar disorder subject heading and the inclusion of psychotic depression in the manic-depressive psychosis subject heading may have distorted the findings, although, if so, it would have been in the direction of overestimating the number of bipolar disorder publications. Searching encompassed all types of publications, including non-empirical ones. Not all relevant journals are covered by the databases searched. Finally, the Journal Citation Reports database includes only journals old enough to have an impact factor, and so misses newer journals such as Bipolar Disorders (1999-present).

The existing literature in this area has used two main indicators of research activity: the extent of research funding and literature size. We found no studies that have directly compared levels of research funding for bipolar disorder and schizophrenia. Pincus \& Fine (1992) examined research funding for mental illness and addictive disorders and found that, although these conditions accounted for $12 \%$ of total health costs, they received only $4.7 \%$ of health research support. We found one study that included a comparison of the literature size on bipolar disorder and schizophrenia (Sprock \& Hermann, 2000). This study was confined to one database, PsycLIT, and contained 1160 papers on bipolar disorder compared with 10722 on schizophrenia over a 7-year period. Two studies have compared the number of papers on leading psychiatric disorders, but neither included a bipolar disorder category (Pincus et al, 1993; Morlino et al, 1997).

What might explain this disparity in research between bipolar disorder and schizophrenia? It has been proposed that illnesses with strong advocates or special interest groups (Gross et al, 1999; Sprock \& Hermann, 2000), 'fashionable' or rare illnesses (Al-Shahi et al, 2001), illnesses with high media or social prominence or those that present a high intellectual challenge (Sprock \& Hermann, 2000) tend to be researched more. However, none of the above factors is an obvious explanation for the lack of research on bipolar disorder relative to schizophrenia.

Some of the disparity is likely to result from schizophrenia's greater overall disease burden, evident in higher hospitalisation rates (Craig et al, 2000), poorer global functioning (Grossman et al, 1991) and greater economic costs (Das Gupta \& Guest, 2002). Clinicians seeing these dayto-day, highly visible aspects of burden may rightly wish to pursue research to combat such a debilitating illness. Types of burden for which bipolar disorder is worse than schizophrenia, such as suicide (Harris \& Barraclough, 1997), excess mortality (Harris \& Barraclough, 1998) and global burden (Murray \& Lopez, 1997), are rarer events or are remote and secondary consequences. This may lower clinicians' perceptions of the seriousness of bipolar disorder, and make it less attractive as a subject for research.

A number of other factors might account for the disparity. Because lithium is a natural substance that cannot be patented, there may be less commercial interest to stimulate research. Our findings provide little support for this hypothesis, because the bipolar disorder:schizophrenia ratio for drug therapy publications on Medline was one of the lowest, at 1:2.3. Another possibility is that bipolar disorder is inherently more difficult to research, owing to the complexity that its episodic nature brings to research design (Calabrese et al, 2001). This cyclicity also may bring recruitment difficulties, with patients too unwell to participate when acutely ill and reluctant to be involved when well. The greater functional impairment of those with schizophrenia makes them a 'captive population' in hospitals and day centres, easily accessible for recruitment into research studies.

The introduction of new research tools, such as neuroimaging, may be an important factor directing research activity (Morlino et al, 1997; Moncrieff \& Crawford, 2001). Neuroimaging findings have been somewhat inconsistent in bipolar disorder (Strakowski et al, 2000). The more consistent schizophrenia findings are likely to have spurred on further neuroimaging research. This speculation is supported by our finding that Medline publications on 'pathology' and 'physiopathology' have the third and fourth highest disparity between schizophrenia and bipolar disorder.

Scientific opportunity is another postulated reason for disparities in research
(Gross et al, 1999). Scientific opportunities often flow from theoretical models. Schizophrenia has attracted intense and long-standing interest, and several family, social and psychological models of aetiology and relapse precipitation have been hypothesised. Research into some of these hypotheses has, in turn, led to the development of evidence-based psychosocial interventions. Psychosocial models in bipolar disorder are fewer and of more recent origin (e.g. Scott, 2001). This notion is supported by our finding that the scientific area with the second highest disparity was psychology. Treatment breakthroughs also have been proposed as a factor influencing research activity, with a surge in schizophrenia research being noted after the introduction of new psychotropic drugs (Moncrieff \& Crawford, 2001).

The development of theoretical models, the emergence of treatment breakthroughs and the overall levels of research activity may be a reflection of the degree of interest that an illness holds for researchers. Depression and the non-psychotic aspects of mania are, to some degree, extensions of normal human experience, whereas psychosis cannot be placed easily on that spectrum. Perhaps the 'other-worldliness' of psychosis holds a fascination for researchers and attracts them to schizophrenia rather than to bipolar disorder, with its more prosaic depression and its less prevalent psychosis. One final possibility is that, by straddling the areas of psychosis (where schizophrenia is the dominant paradigm) and affective disorder (where depression is the dominant paradigm), bipolar disorder has no natural home from which to develop as a research speciality.

It is tempting to speculate whether the comparative dearth of research activity on bipolar disorder also reflects a wider clinical neglect of the condition. Bipolar disorder has received no specific consideration in the UK National Service Framework for Mental Health (Morriss et al, 2002). New resources are being allocated to early intervention in psychosis (Department of Health, 2001), and these services will be geared mostly towards managing young people with schizophrenia. Nationally there are very few specialist services for bipolar disorder. The lack of research in bipolar disorder, therefore, may be intertwined with the level of clinical interest in the condition, and an innovation or breakthrough in one sphere may spur activity in the other. 


\section{ACKNOWLEDGEMENTS}

We thank Sarah White for statistical advice and Sam Martin for advice on literature searching.

\section{REFERENCES}

Al-Shahi, R., Will, R. G. \& Warlow, C. P. (200I) Amount of research interest in rare and common neurological conditions: bibliometric study. BMJ, $\mathbf{3 2 3}$ 1461-1462.

Calabrese, J. R., Rapport, D. J., Shelton, M. D., et a (200I) Evolving methodologies in bipolar disorder maintenance research. British Journal of Psychiatry, 178 (suppl. 4I), sI57-sl63.

Craig, T. J., Bromet, E. J., Fenning, S., et al (2000) is there an association between duration of untreated psychosis and 24-month clinical outcome in a firstadmission series? American Journal of Psychiatry, 157 $60-66$

Das Gupta, R. \& Guest, J. F. (2002) Annual cost of bipolar disorder to UK society. British Journal of Psychiatry, 180, 227-233.

Department of Health (200I) The Mental Health Policy Implementation Guide. London: Department of Health.

Goodwin, G. (2000) Perspectives for clinical research on bipolar disorders in the new millennium. Bipolar Disorders, 2, 302-303.

Gross, C. P., Anderson, G. F. \& Rowe, N. R. (1999)

The relation between funding by the National Institutes of Health and the burden of disease. New England Journal of Medicine, 340, 188I-1887.

Grossman, L. S., Harrow, M., Goldberg, J., et al (1991) Outcome of schizoaffective disorder and two long-term follow-ups: comparisons with outcome of schizophrenia and affective disorders. American journal of Psychiatry, 148, 1359-1365.

Harris, E. C. \& Barraclough, B. (1997) Suicide as an outcome for mental disorders. A meta-analysis. British Journal of Psychiatry, 170, 205-228.

_ \& _ (1998) Excess mortality of mental disorder British Journal of Psychiatry, 173, II-53.

\section{Moncrieff, J. \& Crawford, M. J. (200I) British} psychiatry in the 20th century: observations from a psychiatric journal. Social Science and Medicine, 53, 349-356.

Morlino, M., Lisanti, F., Gogliettino, A., et al (1997) Publication trends of papers on schizophrenia. A 15 -yea analysis of three general psychiatric journals. British Journal of Psychiatry, I7I, 452-456.

\section{CLINICAL IMPLICATIONS}

- The relative paucity of research activity may lead to a poorer evidence base in bipolar disorder.

- Clinicians and researchers should develop and disseminate strategies for overcoming the methodological and practical difficulties inherent in bipolar disorder research.

- The research neglect of bipolar disorder may reflect a lesser clinical interest in the condition.

\section{LIMITATIONS}

- Limitations relating to search strategies, medical subject headings and the types of items included in the databases may have introduced some bias into the findings.

- Changes over time and across scientific fields were investigated using only one database.

- Comprehensive comparative data on disease burden, which would have helped to contextualise the differences in research activity, were not provided.

SARAH CLEMENT, PhD, SWARAN P. SINGH, MRCPsych, TOM BURNS, FRCPsych, Department of Psychiatry, St George's Hospital Medical School, London

Correspondence: Dr Sarah Clement, Department of Psychiatry, St George's Hospital Medical School, CranmerTerrace, London SWI7 ORE,UK. E-mail: s.clement@sghms.ac.uk

(First received 23 April 2002, final revision 27 September 2002, accepted 10 October 2002)

Morriss, R., Marshall, M. \& Harris, A. (2002) Bipolar affective disorder: left out in the cold. BMJ, 324, 6I-62.

Murray, J. L. \& Lopez, A. D. (1997) Global mortality, disability, and the contribution of risk factors: Global Burden of Disease Study. Lancet, 349, 1436-1442.

Pincus, H. A. \& Fine, T. (1992) The 'anatomy' of research funding of mental illness and addictive disorders. Archives of General Psychiatry, 49, 573-579.

\section{, Henderson, B., Blackwood, D., et al (1993)}

Trends in research in two general psychiatric journals in 1969-1990: research on research. American Journal of Psychiatry, I50, 135-142.
Scott, J. (200I) Cognitive therapy as an adjunct to medication in bipolar disorder. British Journal of Psychiatry, 178 (suppl.), sl64-sl68.

Sprock, J. \& Hermann, D. (2000) Relative size of the literatures for psychopathological disorders: numbers of articles pertaining to DSM-IV Diagnostic Categories. Journal of Clinical Psychology, 56, 49I-504.

Strakowski, S. M., DelBello, M. P., Alder, C., et a (2000) Neuroimaging in bipolar disorder. Bipolar Disorders, 2, 148-164. 